\title{
Measurement and Estimation for the Clearance of Radioactive Waste Contaminated with Radioisotopes for Medical Application
}

\author{
Changbum Kim*, MinSeok Park ${ }^{\dagger}$, Gi-sub Kim ${ }^{\dagger}$, Haijo Jung ${ }^{\dagger}$, Seongjoo Jang ${ }^{\dagger}$ \\ *Department of Radiation Application Safety Evaluation, Korea Institute of Nuclear Safety, Daejeon, \\ ${ }^{\dagger}$ Radiation Safety and Section, Korea Institute of Radiological and Medical Sciences, Seoul, \\ ${ }^{\mp}$ Department of Radiology, Dongshin University, Naju, Korea
}

\begin{abstract}
The amounts of radioactive wastes to be disposed in the medical institute have been increased due to development of radiation diagnosis and therapy rapidly. They are produced mostly by the very short lived radioisotopes such as ${ }^{18} \mathrm{~F}$ used in PET/CT, ${ }^{99 m} \mathrm{Tc},{ }^{123} \mathrm{I},{ }^{125} \mathrm{I}$ and ${ }^{201} \mathrm{TI}$, etc. IAEA proposed a criteria for the clearance level of waste which depends on the individual $(10 \mu \mathrm{Sv} / \mathrm{y})$ and collective dose $(1 \mathrm{man}-\mathrm{Sv} / \mathrm{y})$, and concentration of each nuclide (IAEA Safety Series No 111-P-1.1, 1992 and IAEA RS-G-1.7, 2004). Radioactive wastes of ${ }^{18} \mathrm{~F},{ }^{99 \mathrm{~m}} \mathrm{TC},{ }^{123} \mathrm{I},{ }^{125} \mathrm{I}$ and ${ }^{201} \mathrm{TI}$ in the several types of container like Marinelli beaker, vial and plastic, were collected to measure the concentration of the waste of each nuclide in accordance with IAEA criteria. The measurement method and procedure of determining specific activity of the wastes using gamma emitters like MCA, gamma counter and beta emitters were developed. For the efficiency calibration of the detectors, CRM (certified reference material) which has the same dimension and shape was provided by Korea Research Institute of Standards and Science (KRISS). Correction factor of the radioactivity decay was calculated based on the measurement results, and the consideration of mutual relation with theoretical equation. The result of this study will be proposed as ISO standard.
\end{abstract}

Key Words: Radioactive waste, Self disposal, Medical radioactive isotope, Specific radioactivity

\section{서 론}

최근 첨단 진단영상장비인 양전자방출단층촬영기/컴퓨 터단층촬영기(PET/CT: Positron Emission Tomography/Computed Tomography)가 점진적으로 보급됨에 따라 반감기 109.8 분 불소 $\left({ }^{18} \mathrm{~F}\right)$ 표지화합물 방사성의약품의 이용이 확 대되어 왔다. 이에 따라서 각 병원 핵의학과에서 방사성의 약품 관련 진단 및 치료 목적의 방사성폐기물의 발생이 무 시할 수 없을 정도로 증가하고 있다. ${ }^{1,2)}$ 방사성폐기물은 환 경 및 인체에 해로운 영향을 끼칠 수 있으므로 발생, 보관

This project is partially supported by the National Standard Infrastructure Enhancement Program provided through the Ministry of Trade, Industry and Energy, Korea.

Received 4 February 2014, Accepted 6 March 2014

Correspondence: Seongjoo Jang (sjjang@dsu.ac.kr) Tel: 82-61-330-3321, Fax: 82-61-330-3309

(C) This is an Open-Access article distributed under the terms of the Creative Commons Attribution Non-Commercial License (http://creativecommons.org/licenses/by-nc/3.0) which permits unrestricted non-commercial use, distribution, and reproduction in any medium, provided the original work is properly cited.
및 처분에 이르기까지 안전관리의 중요성이 대두되고 있 다. ${ }^{3,4)}$ 의료 방사성폐기물의 경우, 방사성물질을 단독으로 사용하기보다는 특정 시료와 혼합하거나 환자의 혈액과 섞 어 사용하기 때문에 감염성 폐기물로도 분류가 될 수 있어 폐기물 관리에 있어 어려움을 겪고 있는 실정이다. ${ }^{5-7)}$

의료용 방사성동위원소의 대부분은 상대적으로 반감기 가 짧고 방사성독성이 없다는 측면에서 단기간 경과하면 자체처분의 방법으로 쉽게 처리할 수 있는 장점이 있다. ${ }^{7}$ 의료용 개봉선원과 관련된 방사성폐기물은 대부분 이와 같 이 자체처분의 방법으로 처리하고 있으며, 미국이나 프랑 스 등 대부분의 선진국에서도 적용하고 있다. 즉, 반감기가 길지 않은 개봉선원과 관련된 방사성폐기물을 대상으로 위 험도가 충분히 배제될 수 있는 수준 이하로 방사능 농도가 감쇠될 때까지 안전하게 보관하였다가 소각 등의 방법으로 처리한다. 이 경우, 개인선량과 집단선량을 기반으로 한 IAEA 규정8)을 적용하고 있으며, 이에 근거하여 우리나라 의 규제기준을 만들어 1997년부터 시행하고 있다. 다만, 선 량에 근거한 IAEA 규정에 부합하기 위해서는 선량평가 절 
차서의 개발과 안전성 평가라는 전문성이 요구되며, 그 차 이도 작지 않을 것이므로 이용의 편리성을 고려하여 2004 년 핵종별 방사능농도에 근거한 새로운 IAEA 규정이 발간 되었다. ${ }^{9}$ 이 규정에서는 250 여 인공 방사성핵종에 대한 규 제해제의 기준을 정량적으로 제시하였는데, 해당 방사성핵 종의 위해도 및 독성에 따라 $0.1,1,10,100$, 그리고, 1,000 $\mathrm{Bq} / \mathrm{g}$ 등 5 개 군으로 분류하고 있다. 따라서 자체처분일 평 가를 명확하게 평가하여 시행할 수 있다는 장점이 있으나, 방사능농도 측정 장비를 별도로 구비하여야 하는 비용적인 부담이 제기되어 개개의 사업소에서 시행하기에는 어려움 이 있다.

현재 관행적으로 이루어지고 있는 자체처분에서 선량평 가는 물론 방사능 농도의 분석도 전혀 이루어지지 않고 있 다. 방사성폐기물 발생시점에서의 방사능농도를 보수적으 로 산정하고 이론적인 방사능 감쇠에 근거하여 일정 보관 기간이 경과하는 시점에 자체처분을 시행하고 있다. 이와 같은 방법에 문제점이 있다거나 해당 규정을 위반할 우려 가 있지는 않지만, 관행에 따르다 보니 핵종 및 폐기물별의 정확한 잔존 방사능량을 측정한 사례가 전무하였고, 결국 은 측정방법이나 방사능량의 감쇠상태를 고찰하여 자체처 분 시점을 정확하게 인지하지 못한 어려움이 있었다. 또한 방사능 측정을 기반으로 폐기물을 보관 및 처분하고 있지 않아서 불필요하게 적체되는 폐기물의 수량이 상당하다. 따라서 제한된 보관공간을 사용하는 의료기관에서는 폐기 물 보관이 어려운 경우도 발생하고 있다.

본 연구에서는 주요 의료용 방사성폐기물에 대하여 다양 한 방사성핵종 및 사용용기 별로 방사능 측정방법을 개발 하고 그에 따라 측정하는 한편, 측정에 영향을 미치는 인자 들을 고찰하여 자체처분을 위한 적정 보관기간을 평가하고
자 한다.

\section{재료 및 방법}

방사성폐기물의 방사능농도 분석대상으로 최근 핵의학 검사에서 PET 또는 PET/CT 영상장비에 다양하게 사용되 고 있는 방사성 ${ }^{18} \mathrm{~F}$ 표지화합물을 비롯하여, 감마카메라, 단일광자방출단층촬영기(SPECT: Single Photon Emission Computed Tomography) 및 방사성동위원소 치료에 사용하 는 ${ }^{99 \mathrm{~m}} \mathrm{Tc},{ }^{123} \mathrm{I},{ }^{125} \mathrm{I},{ }^{201} \mathrm{~T}$ 등의 방사성핵종이 묻어있거나 남아 있는 형태로 방사능 핵종에 오염된 약 45 종의 의료용 방사 성폐기물에 대한 최적의 방사능 측정방법을 고찰하고, 자 체처분을 위한 합리적인 처리절차를 수립한다.

\section{1. 방사성폐기물 수집 및 측정 용기}

의료현장에서 개봉선원의 사용빈도가 가장 높은 핵의학 검사실 및 옥소치료병실에서 발생하는 방사성폐기물을 2012년 8월에서 2013년 2월 사이에 한국원자력의학원 핵의 학과에서 수집하였다. 방사성폐기물은 핵의학 진단 검사를 위한 주사 후 발생하는 면솜, 주사기 그리고 동맥 내 수액 세트(주사기+3 Way 스톱콕)와 같이 방사성동위원소 이용 후 발생하는 것을 주로 수집하였다. 이 경우 연관되는 방사 성동위원소는 PET 검사용 ${ }^{18} \mathrm{~F}$, 감마카메라 및 단일광자방 출단층촬영용 ${ }^{99 \mathrm{~m}} \mathrm{Tc},{ }^{123} \mathrm{I}$, 그리고 ${ }^{201} \mathrm{Tl}$, 체외검사용 (in vitro) ${ }^{125} \mathrm{I}$ 가 있다.

수집한 방사성폐기물의 용기는 다양한 형태를 가지고 있 으므로, 이를 표준 측정하기 위해서는 측정시스템에 알맞 은 일괄된 측정용기에 담아 측정하는 것이 중요하다. 본 연 구에서 방사성폐기물을 $1 \mathrm{~L}$ 마리넬리(Marinelli) 비커, 20

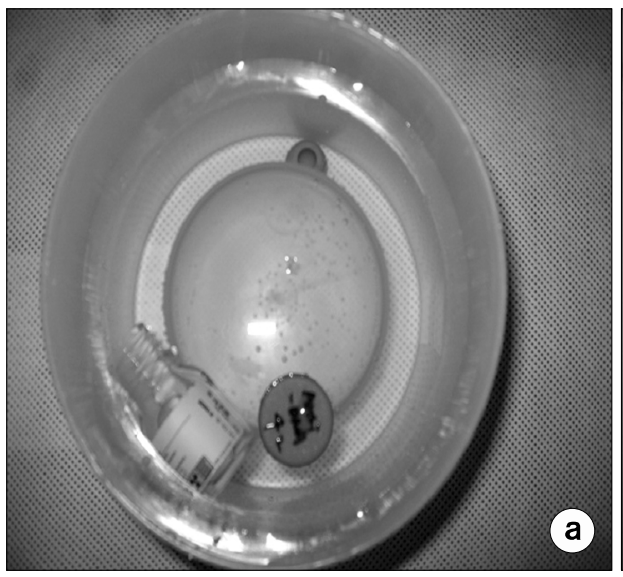

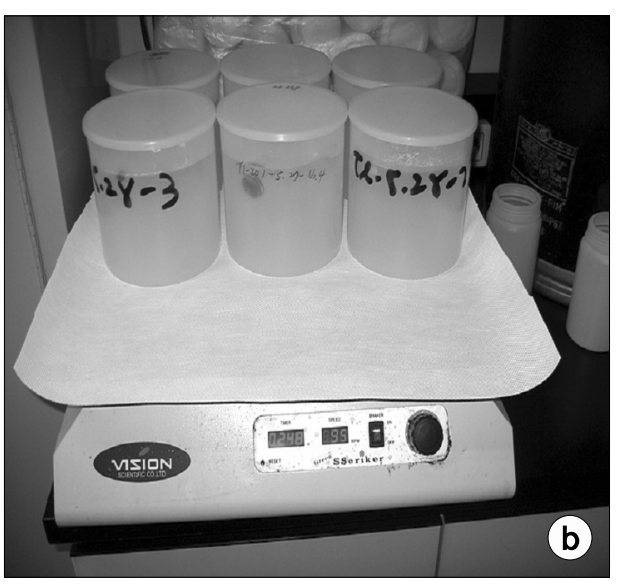

$-9-$
Fig. 1. The photographies of Marinelli beaker containing the radioactive waste from nuclear medicine department. (a) Marinelli beaker with radioactive wasted container and saline solution, (b) the dissolution and diffusion of radioactive nuclide in saline solution using a stirrer. 
$\mathrm{ml}$ 유리용기(vial) 또는 $90 \mathrm{ml}$ 플라스틱(U8) 비커를 주로 사 용하여 다중파고분석기(MCA: Multi-Channel Analyzer) 측정 시스템에 위치시켜서 측정하였다. 측정 조건을 동일하게 하기 위하여 측정용기에 시료를 넣어 증류수를 채운 후 각 각 일정한 측정 부피를 맞추었다(Fig. 1).

\section{2. 방사능 측정 방법 및 절차}

본 연구에서는 방사능이 비교적 크지 않고 반감기가 짧 은 방사성폐기물을 대상으로 하고 있으므로 상대적으로 정 밀한 측정 장비가 필요하다. 방사성폐기물의 방사능을 정 확하고 효율적으로 측정하기 위해서는 측정 환경 및 기술 적 특성을 고려하여야 한다. 구체적으로 폐기물 무게의 측 정, 폐기물에 묻어있는 오염 핵종의 특성, 방사능 측정에 영향을 미치는 자연방사선(background radiation), 적정한 방 사능 측정 장비의 선정, 폐기물의 측정 기하학적 구조 등을 고려하여야 한다. 또한 인증 표준물질(CRM: Certified Reference Materials)을 이용하여 측정값의 정확성을 높이고자 하였다. 아래와 같은 과정을 통해 의료용으로 사용하는 주 요 핵종과 관련된 폐기물의 잔존 방사능량 범위를 고찰하 였으며, 또한 이를 이용하여 이론 및 실험적으로 자체처분 을 위한 최적의 보관 시기를 추정한다.

1) 다중파고분석기 $(\mathrm{MCA})$ 를 이용한 감마 방사능 측정: 의료현장에서 수집한 방사능폐기물은 MCA (HPGe Detector DSA 1000, Canberra, USA)를 사용하여 측정하였다. 효 율교정은 2012. 07. 06에 한국원자력연구원에서 교정한 교 정데이터를 기반으로 하였다. MCA로 측정되는 폐기물로 는 ${ }^{125} \mathrm{I}$ 핵종을 제외한 ${ }^{18} \mathrm{~F},{ }^{99 \mathrm{~m}} \mathrm{Tc},{ }^{123} \mathrm{I}$ 그리고 ${ }^{201} \mathrm{Tl}$ 로 효율교 정이 된 용기에 담아 측정을 하였다. 방사성폐기물 시료 준 비와 측정 과정은 아래와 같다.

(1) 핵의학과 검사 일정 확인 후 폐기물 발생 직후 바로 수거한다.

(2) 수거된 방사성폐기물은 전자저울(Model AJH-2200E$\mathrm{D}, \mathrm{Vibra}, \mathrm{Japan})$ 을 이용하여 무게를 각 3 회 측정하고 고유 코드를 할당하였다(핵종 - 발생일자 - 순서).

(3) 방사능이 높은 방사성폐기물은 차폐 가능한 용기에 서 1 3일 후 2)에서와 같이 수행하였다.

(4) 주사용 솜은 $20 \mathrm{ml}$ 유리용기에 수거하였다 $(20 \mathrm{ml}$ 용 기 측정효율 적용).

(5) $20 \mathrm{ml}$ 유리용기와 동일한 크기의 유리용기와 플라스 틱 병은 전처리 없이 측정하였다 $(20 \mathrm{ml}$ 용기 측정효율 적 용).

(6) 종이컵, 비닐장갑 등은 $90 \mathrm{~mm} \mathrm{U8}$ 플라스틱 용기에
수거하였다(90 mm U8용기 측정효율 적용).

(7) 각종 크기의 주사기, 유리용기, 플라스틱 병은 $1 \mathrm{~L}$ 마 리넬리 용기로 수거하고 다음과 같이 전처리 후 측정하였 다 $(1 \mathrm{~L}$ 마리넬리 용기 측정효율 적용).

(1) 마르리넨 용기에 증류수를 $1,000 \mathrm{~g}$ 넣고, 2)에서와 같 이 무게를 측정하였다.

(2) 반감기에 따라 보관기간이 다르지만, 최소 2 시간 후 수거된 폐기물을 넣은 $1 \mathrm{~L}$ 마리넬리 용기를 방사능이 균질 하게 섞이도록 교반기(Sseriker: Vision scientific Co. Ltd, Korea) 65 RPM으로 6시간 교반하였다.

(3) 교반기에서 균일하게 섞인 시료를 1 2시간 경과 후 $\mathrm{MCA}$ 를 이용하여 계측기의 불감시간(dead time)이 $3 \%$ 이하 인 경우에 측정하였다.

2) 감마계수기를 이용한 감마 방사능 측정: 의료 현장의 방사성폐기물이 발생되는 위치에서 체외검사에 사용된 ${ }^{125} \mathrm{I}$ 핵종 폐기물의 경우 감마계수기(Gamma counter: Packard Cobra II, USA)를 이용하여 측정하였다. 측정기 효율은 ${ }^{125} \mathrm{I}$ 핵종 표준선원을 이용한 측정결과와의 보정값으로 구하였 으며 표준선원 측정값을 비교하였을 때 $77 \%$ 의 효율을 나 타내었다. 감마계수기로 측정할 경우 분당계수값(cpm: counts per minute)값으로 데이터가 산출이 되는데 이를 아래 식에 의하여 비방사능 $(\mathrm{Bq} / \mathrm{g})$ 값으로 환산하여 비교평가 하였다.

A $($ specific activity $: \mathrm{Bq} / \mathrm{g})=$
$\frac{\text { count measurement }(\text { count per min. })}{(60 \mathrm{~s} / \mathrm{min} .) \times(\text { efficiency of detector }) \times \mathrm{sample} \text { mass }}$

3) 베타입자 방출 방사성폐기물의 방사능 측정: 유리용 기, 주사기, 주사바늘 등에 남아 있는 베타입자 방출 핵종 은 짧은 비정(range)을 지니고 있어 폐기물용기 자체에 흡 수되기 때문에 방사능 측정이 매우 어렵다. 따라서 이러한 경우에는 사용한 방사능량을 고려하고 남은 양을 추정하여 보관기간을 산정한다. 보관기간 산정은 방사성폐기물의 자 체 처분에 관한 규정(원자력안전위원회 고시 제2012-59호) 에 따라 계산하며 이때 계산결과에 가중치(safety factor) 1.2 를 곱하여 보관기간으로 정한다. ${ }^{10}$

\section{3. 측정 시스템 효율 교정을 위한 인증 표준물질 제작}

정확한 방사능 측정을 위하여, 측정시스템 및 측정하고 자하는 용기에 알맞은 측정효율 교정이 필요하다. 효율 교 정을 위해 의료용 방사성폐기물 핵종의 방사능 측정용기와 동일한 크기와 모양의 인증표준물질(CRM: Certified Refe- 
rence Materials)을 국가측정표준기관(한국표준과학연구원) 에 의뢰 및 제작하고, 이를 이용하여 측정하는 방사능검출 기에 대한 교정을 실시하였다(Fig. 2). 교정은 2012년 7월 6 일 $20 \mathrm{~mm}$ 유리용기(vial), $90 \mathrm{ml}$ (U8) 플라스틱 용기, $1 \mathrm{~L}$ 마리넬리 비커에 대하여 수행하였다. $90 \mathrm{ml} \mathrm{U8}$ 플라스틱 용기 및 $1 \mathrm{~L}$ 마리넬리 비커는 ${ }^{18} \mathrm{~F},{ }^{99 \mathrm{~m}} \mathrm{Tc},{ }^{123} \mathrm{I},{ }^{125} \mathrm{I}$ 그리고 ${ }^{201} \mathrm{Tl}$ 등의 시료를 측정하기 위하여 인증표준물질을 제작하 여 효율교정을 실시하였다. 또한, ${ }^{125} \mathrm{I}$ 핵종 측정을 위해서 도 $1 \mathrm{~L}$ 마리넬리 비커의 인증표준물질을 제작하여 자체적 으로 효율교정을 실시하였다.

\section{4. 방사성폐기물의 자체처분 보관기간 산출}

방사성폐기물의 자체처분을 위한 보관기간은 방사성폐기

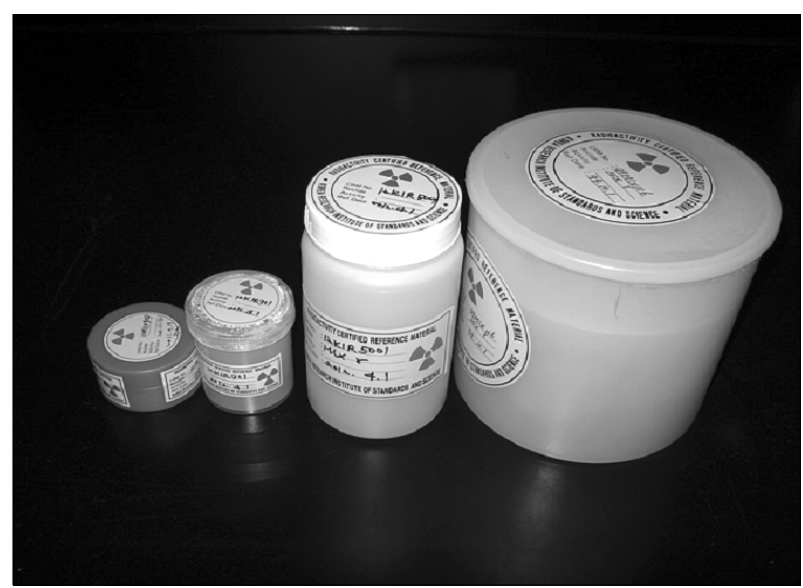

Fig. 2. The photography of various CRMs for the efficiency measurement of various measuring containers and the detection system.
물의 자체처분에 관한 규정(원자력안전위원회고시 제 2012-59호)에 따라 산출하였으며 아래의 식과 같다. ${ }^{9)}$

$$
\begin{gathered}
\text { 보관기간 }(\text { 일 })= \\
+ \text { 반감기 }(\text { 일 }) \times \text { 가중계수 }
\end{gathered}
$$

방사성폐기물의 방사능 농도는 $\mathrm{MCA}$ 로 측정한 값을 사 용하며 제한농도는 원자력안전위원회고시에 따라 적용한 다. 본 연구에서 고려한 방사성폐기물의 핵종은 ${ }^{18} \mathrm{~F},{ }^{99 \mathrm{~m}} \mathrm{Tc}$, ${ }^{123} \mathrm{I},{ }^{125} \mathrm{I}$ 그리고 ${ }^{201} \mathrm{Tl}$ 이며 각각의 제한농도는 규정에 따라 모두 $100 \mathrm{~Bq} / \mathrm{g}$ 이다. 가중계수는 주사기, 유리용기와 같은 베타방출핵종의 경우 1.2 , 그 이외의 경우는 1.45 를 적용하 여 산출한다. ${ }^{10)}$

\section{결과 및 고찰}

의료현장에 발생하는 방사성폐기물을 각각의 방사성동 위원소 별, 그리고 발생 유형 별로 나누어 분류, 측정하였 다. 각 방사성폐기물에 대한 방사능측정은 방사성폐기물이 발생한 시점과 자체처분을 위하여 인출하는 시점, 그리고 그 중간에 해당하는 시점 등 총 3 번 실시하였다. 각각의 폐 기물 시료의 측정결과를 바탕으로 자체처분가능일을 산출 하였고 이를 평균하여 나타내었다. 시료의 측정과정에서 방사성폐기물은 임의로 희석하거나 혹은 혼합하는 등의 인 위적인 처리과정은 배제하였다.

Table 1은 PET 또는 PET/CT검사에 사용하는 포도당유사 체(FDG: Fluorodeoxyglucose)의 방사성표지물 핵종 ${ }^{18} \mathrm{~F}$ 의 방 사성폐기물에 대한 방사능 측정 결과이다. ${ }^{18} \mathrm{~F}$ 방사성폐기 물의 측정결과 $5 \mathrm{ml}$ 주사기에서 가장 높은 방사능농도 값

Table 1. Radioactivity measurement according to the incident types of ${ }^{18} \mathrm{~F}$ radioactive waste.

\begin{tabular}{lccc}
\hline \multicolumn{1}{c}{ Type of radioactive waste } & Syringe cotton ball & Syringe $(5 \mathrm{ml})$ & Syringe $(10 \mathrm{ml}+3 \mathrm{Way})$ \\
\hline No. of sample $(\mathrm{n})$ & 20 & 20 & 20 \\
Specific radioactivity $(\mathrm{Bq} / \mathrm{g}): \mathrm{m} \pm \sigma$ & $362 \pm 4$ & $8.14 \times 10^{5} \pm 2.78 \times 10^{5}$ & $8.32 \times 10^{4} \pm 3.39 \times 10^{4}$ \\
(Mean) storage period to clearance level (day) & 0.11 & 1.43 & 1.06 \\
\hline \hline
\end{tabular}

Table 2. Radioactivity measurement according to the incident types of ${ }^{99 \mathrm{~m}} \mathrm{Tc}$ radioactive waste.

\begin{tabular}{lccc}
\hline \multicolumn{1}{c}{ Type of radioactive waste } & Syringe cotton ball & Syringe $(1 \mathrm{ml})$ & Syringe $(5 \mathrm{ml})$ \\
\hline No. of sample $(\mathrm{n})$ & 14 & 14 & 45 \\
Specific radioactivity $(\mathrm{Bq} / \mathrm{g}): \mathrm{m} \pm \sigma$ & $6.38 \times 10^{6} \pm 1.8277$ & $5.57 \times 10^{4} \pm 1.775$ & $1.34 \times 10^{7} \pm 5.13 \times 10^{6}$ \\
(Mean) storage period to clearance level (day) & 3.44 & 1.86 & 6.17 \\
\hline \hline
\end{tabular}


을 나타내었다. 하지만 단 반감기 핵종으로 최대 1.43 일 정 도면 자체처분이 가능하다.

Table 2 는 ${ }^{99 \mathrm{~m}} \mathrm{Tc}$ 방사성폐기물의 측정결과를 보여준다. 5 $\mathrm{ml}$ 주사기에서 가장 높은 측정결과를 나타내었다. 또한 주 사 후 환자 지혈용으로 사용하는 면솜의 경우도 비교적 높

Table 3. Radioactivity measurement according to the incident types of ${ }^{123}$ I radioactive waste.

\begin{tabular}{lcc}
\hline \multicolumn{1}{c}{$\begin{array}{c}\text { Type of radioactive } \\
\text { waste }\end{array}$} & $\begin{array}{c}\text { Syringe cotton } \\
\text { ball }\end{array}$ & $\begin{array}{c}\text { Syringe } \\
(1 \mathrm{ml})\end{array}$ \\
\hline $\begin{array}{l}\text { No. of sample (n) } \\
\text { Specific radioactivity } \\
(\mathrm{Bq} / \mathrm{g}): \mathrm{m} \pm \sigma\end{array}$ & 20 & 20 \\
$\begin{array}{l}\text { (Mean) storage period to } \\
\text { clearance level (day) }\end{array}$ & $7.53 \times 10^{5} \pm 1.0410^{6}$ & $6.33 \times 10^{6} \pm 4.08 \times 10^{6}$ \\
\hline \hline
\end{tabular}

은 측정결과를 나타내었다. ${ }^{99 \mathrm{~m}} \mathrm{Tc}$ 핵종의 경우 최대 6.17 일 이면 자체폐기가 가능함을 알 수 있다.

Table 3은 ${ }^{123} \mathrm{I}$ 방사성폐기물의 측정결과로 $1 \mathrm{ml}$ 주사기에 서 최대 측정결과를 나타내었다. ${ }^{123} \mathrm{I}$ 핵종은 $13.2 \mathrm{hr}$ 의 반감 기를 갖고 있는 단반감기 핵종으로 최대 12.55 일이면 자체 처분이 가능하다.

Table 4 는 ${ }^{201} \mathrm{Tl}$ 핵종에 대한 방사성폐기물의 측정결과이 다. ${ }^{201} \mathrm{Tl}$ 핵종의 경우 ${ }^{18} \mathrm{~F},{ }^{99 \mathrm{~m}} \mathrm{Tc},{ }^{123} \mathrm{I}$ 핵종과 비교하였을 경 우 $72.91 \mathrm{hr}$ 의 비교적 긴 반감기를 가지고 있으며, 전자포 획 붕괴과정을 통하여 ${ }^{202} \mathrm{Tl}$ 딸핵종을 발생시킨다. 발생하 는 ${ }^{202} \mathrm{Tl}$ 핵종의 경우 12.23 일의 긴 반감기를 가지고 있어 ${ }^{201} \mathrm{Tl}$ 핵종의 자체 처분 가능일 산출에는 ${ }^{202} \mathrm{Tl}$ 핵종의 방사 능 기여도 고려해 주어야 한다. ${ }^{201} \mathrm{Tl}$ 핵종 사용 주사기(3 $\mathrm{ml}+3$ way)의 경우가 최대 자체처분 가능일은 80.03 일이다. 지금까지 방사성핵종의 체외검사 및 치료과정에서 발생

Table 4. Radioactivity measurement according to the incident types of ${ }^{201} \mathrm{Tl}$ radioactive waste.

\begin{tabular}{|c|c|c|c|}
\hline Radionuclide & \multicolumn{3}{|c|}{ Tl-201 } \\
\hline Type of radioactive waste & Syringe cotton ball & Syringe ( $3 \mathrm{ml}+3$ Way) & Syringe (10 $\mathrm{ml}+3$ Way) \\
\hline No. of sample (n) & 4 & 6 & 3 \\
\hline Specific radioactivity $(\mathrm{Bq} / \mathrm{g}): \mathrm{m} \pm \sigma$ & $1.65 \times 10^{5} \pm 2.51 \times 10^{5}$ & $4.31 \times 10^{5} \pm 2.30 \times 10^{5}$ & $4.64 \times 10^{4} \pm 2.52 \times 10^{4}$ \\
\hline Radionuclide & \multicolumn{3}{|c|}{ Tl-202 } \\
\hline Type of radioactive waste & Syringe cotton ball & Syringe ( $3 \mathrm{ml}+3$ Way) & Syringe (10 $\mathrm{ml}+3$ Way) \\
\hline No. of sample (n) & 4 & 6 & 3 \\
\hline Specific radioactivity $(\mathrm{Bq} / \mathrm{g}): \mathrm{m} \pm \sigma$ & $\mathrm{N} / \mathrm{A}^{*}$ & $1.00 \times 10^{4} \pm 2.07 \times 10^{4}$ & $1.52 \times 10^{2} \pm 9.40 \times 10^{1}$ \\
\hline (Mean) storage period to clearance level (day) & - & 80.03 & 11.45 \\
\hline
\end{tabular}

${ }^{*}$ N/A: Not Available.

Table 5. Radioactivity measurements according to the incident types of ${ }^{125} \mathrm{I}$ (in vitro) radioactive waste.

\begin{tabular}{|c|c|c|c|c|c|}
\hline \multirow{2}{*}{ Type of sample } & \multirow{2}{*}{$\begin{array}{c}\text { No. of } \\
\text { sample (n) }\end{array}$} & \multicolumn{3}{|c|}{ Specific radioactivity $(\mathrm{Bq} / \mathrm{g})$} & \multirow{2}{*}{$\begin{array}{l}\text { (Mean) storage period to } \\
\text { clearance level (day) }\end{array}$} \\
\hline & & Mean $\pm S D^{*}$ & Max. & Min. & \\
\hline $\mathrm{T} 3$ & 100 & $51.6 \pm 27.1$ & 130.2 & 5.6 & 0 \\
\hline $\mathrm{T} 4$ & 100 & $44.5 \pm 24.3$ & 94.3 & 10.0 & 0 \\
\hline TSH & 100 & $20.5 \pm 51.1$ & 282.8 & 0.2 & 0 \\
\hline FREE T4 & 100 & $56.9 \pm 27.0$ & 140.9 & 6.6 & 0 \\
\hline Anti-TG & 100 & $11.7 \pm 22.3$ & 114.3 & 0.5 & 0 \\
\hline Anti-TMS & 100 & $34.4 \pm 24.1$ & 83.8 & 1.4 & 0 \\
\hline TG & 100 & $15.2 \pm 52.1$ & 315.2 & 0.1 & 0 \\
\hline CEA & 100 & $21.1 \pm 47.5$ & 208.1 & 0.4 & 0 \\
\hline CA19-9 & 44 & $23.8 \pm 52.7$ & 262.4 & 1.3 & 0 \\
\hline $\mathrm{LH}$ & 54 & $18.6 \pm 39.5$ & 187.7 & 0.3 & 0 \\
\hline FSH & 54 & $16.9 \pm 34.1$ & 171.3 & 1.2 & 0 \\
\hline
\end{tabular}

*SD: Standard deviation. 
Table 6. Types of radioactive waste sample occurred from the in vitro examinations of ${ }^{125} \mathrm{I}$.

\begin{tabular}{lll}
\hline \hline Types of Examination & Reagent & \multicolumn{1}{c}{ Purpose of examination } \\
\hline Hormone test & T3 & Thyroid function Test \\
& T4 & Thyroid function Test \\
& TSH & Test for syndrome of inappropriate secretion of TSH \\
& Free T4 & Thyroid function Test \\
& TG & Test for Metastatic cancer by thyroid cancer \\
& LH & Infertility evaluation \\
Test for cancer, hepatitis, and anemia & FSH & Infertility evaluation \\
& Anti-TMS & Autoimmunethyroiditis Test \\
& CEA & Autoimmunethyroiditis Test \\
& CA19-9 & Test for metastatic cancer for liver \\
\hline \hline
\end{tabular}

하는 방사성폐기물의 방사능농도를 측정하였고 자체처분 가능일을 산출하였다. 다음의 Table 5는 방사성핵종을 이용 하여 체외검사를 실시하는 경우 발생하는 방사성폐기물에 대한 측정결과 및 자체처분가능일 산출 결과이다. 체외 검 사의 경우 다양한 시료와 방사성핵종을 섞어 사용하므로 여러 유형의 방사성폐기물(Table 6)에 대한 결과를 각각 산 출하였다.

체외검사용 ${ }^{125} \mathrm{I}$ 핵종의 비방사능평균 측정값은 체내검사 용에 비해 매우 낮은 수치를 나타냄을 확인할 수 있었다. 또한 59.4일의 긴 반감기에도 불구하고 자체처분가능일 산 출에서 즉시 처분이 가능한 것으로 나타났다.

의료현장에서 발생되는 여러 방사성폐기물을 측정, 분석 한 결과 ${ }^{201} \mathrm{Tl}$ 핵종 폐기물을 제외한 ${ }^{18} \mathrm{~F},{ }^{99 \mathrm{~m}} \mathrm{Tc},{ }^{123} \mathrm{I}$ 그리고 ${ }^{125} \mathrm{I}$ 핵종 폐기물은 최대 14 일 이후에 처분이 가능함을 확 인 할 수 있었다. 특히 ${ }^{18} \mathrm{~F}$ 그리고 체외검사용 핵종인 ${ }^{125} \mathrm{I}$ 로 인해 발생하는 방사성폐기물은 즉시 자체처분이 가능함을 확인 할 수 있었다. 현행 처분과 비교하여 짧은 주기로 자 체처분이 가능하며 의료현장에서 발생하는 폐기물의 방사 성오염도가 높지 않음을 확인할 수 있다. ${ }^{201} \mathrm{Tl}$ 핵종 폐기물 의 경우 핵종 붕괴로 발생하는 ${ }^{202} \mathrm{Tl}$ 로 인한 방사능 오염으 로 자체처분 기간이 길어지며, 환자에게 핵종을 주사할 경 우 발생하는 주사기의 오염이 가장 높으며, 지혈용 면솜의 경우는 오염도가 낮아 평균 4 일 이내에 자체처분이 가능함 을 확인할 수 있다.

\section{결 론}

폐기물의 효율적 관리를 위한 표준 절차를 수립하기 위 하여 앞으로도 다양한 핵종 및 종류의 의료용 방사성폐기
물에 대한 방사능 농도를 측정하는 노력은 물론 보편적인 의료현장에서 사용할 수 있는 방사성폐기물자체처분에 대 한 연구를 지속하여야 할 것이다. 본 연구를 통하여 국내는 물론 전 세계적으로도 의료용 방사성폐기물에 대해 처음으 로 측정방법을 설정하고 시도되었다는 점에서 향후 유사 연구에 큰 도움이 될 것으로 보인다. 특히, 이 연구에서 시 도한 측정방법과 이를 적용한 측정결과는 ISO (International Organization for Standardization) 표준으로 제안하고자 한다.

\section{References}

1. Park JK, Kim SK, et al: Enhancement of the Early/Precise Diagnosis Based on the Measurement of SUVs in F-18 FDG PET/CT Whole-body Image. J Korean J Med Phys 24(3): 176-182 (2013)

2. Kim SJ, Han EO: Changes in External Radiation Dose Rate for PET-CT Test Patients. J Radiation Protection 37(2):103-107 (2012)

3. Shapito J: Radiation Protection: A guide for scientists, regulator and Physicians, 4th ed, Harvard University Press (2002), pp. 359-371

4. IAEA Safety Series No.40: Applying Radiation Safety Standards in Nuclear Medicine (2005)

5. Ravichandran R, Binukumar JP, Sreeram R, Arunkumar LS: An overview of radioactive waste disposal procedures of a nuclear medicine J Med Phys 36(2):95-99 (2011)

6. IAEA Safety Series No.111: Classification of Radioactive Waste (1994)

7. IAEA TECDOC-1183: Management of radioactive waste from the use of radionuclides in medicine (2000)

8. IAEA Safety Series No.111-P-1.1: Application of exemption principles to the recycle and reuse of materials from nuclear facilities (1992)

9. IAEA Safety Guide RS-G-1.7: Application of the concepts of exclusion, exemption and clearance (2004) 
Changbum Kim, et al : Measurement and Estimation of Radioactive Waste in Medical Field

10. http://www.nssc.go.kr/nssc/information/law4_4.jsp, The code of

Regulation for the clearance of radioactive waste (2012) nuclear safety and security commission Jae2012-59Ho:

\section{의료용 방사성폐기물 자체처분을 위한 방사능 측정 및 평가}

*한국원자력 안전기술원 방사선원평가실, ${ }^{\dagger}$ 한국원자력의학원 방사선안전관리팀, ${ }^{\ddagger}$ 동신대학교 방사선학과

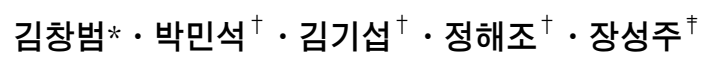

의료분야에서 방사선 진료기술의 발전에 따라 방사성폐기물의 수량은 급속히 증가하고 있다. 방사성폐기물에는 주로 $\mathrm{PET} / \mathrm{CT}$ 에 사용하는 ${ }^{18} \mathrm{~F}$ 을 비롯하여 핵의학검사에 사용하는 ${ }^{99 \mathrm{~m}} \mathrm{Tc}$ 등과 같이 반감기가 매우 짧은 방사성동위원소가 함유 되어 있다. 이를 처분하기 위하여 국제원자력기구(IAEA)는 개인선량(10 $\mu \mathrm{Sv} / \mathrm{y})$ 및 집단선량 $(1 \mathrm{man}-\mathrm{Sv} / \mathrm{y})$ 과 핵종별 농도에 근거하여 각각 폐기물의 규제해제기준을 제시(IAEA Safety Series No 111-P-1.1, 1992 및 IAEA RS-G-1.7, 2004)하였다. 이 연구에서는 IAEA 기준에 따른 방사능농도를 측정하기 위하여, ${ }^{18} \mathrm{~F},{ }^{99 \mathrm{~m}} \mathrm{TC},{ }^{123} \mathrm{I},{ }^{125} \mid$ 및 ${ }^{201} \mathrm{Tl}$ 관련 방사성폐기물을 수집하 고 측정용기를 준비하였다. 그리고 $\mathrm{MCA}$ 를 이용한 감마방사능 측정, 감마계수기를 이용한 감마방사능 측정, 베타입자 방 출 핵종의 방사능 측정방법 및 절차를 수립하고, 표준물질을 제작하여 교정하였다. 측정결과를 근거로 방사능 감쇠 유도 식을 산출하였으며, 이를 이론식과 대비하여 고찰하였다. 이 연구 결과는 ISO 표준으로 추진할 예정이다.

중심단어: 방사성폐기물, 자체처분, 의료 방사성동위원소, 비방사능 